\title{
Cancer in a polyp of the large intestine - an interdisciplinary decision problem
}

\author{
Przemysław Stefaniak ${ }^{1}$, Hanna Majewska², Dariusz Zadrożny ${ }^{1,3}$, Janusz Godlewski ${ }^{1,4}$ \\ ${ }^{1}$ Surgical Oncology Clinic, Hospital Ministry of Internal Affairs with Warmia and Mazury Oncology Centre, Olsztyn, Poland \\ 2Department of Pathomorphology, School of Medicine, University of Warmia and Mazury, Olsztyn, Poland \\ ${ }^{3}$ Department of Oncology, School of Medicine, University of Warmia and Mazury, Olsztyn, Poland \\ ${ }^{4}$ Department of Human Histology and Embryology, School of Medicine, University of Warmia and Mazury, Olsztyn, Poland
}

Gastroenterology Rev 2021; 16 (4): 306-310

DOI: https://doi.org/10.5114/pg.2021.111481

Key words: malignant colorectal polyp, colonoscopy.

Address for correspondence: Dr. Przemysław Stefaniak, Surgical Oncology Clinic, Hospital Ministry of Internal Affairs with Warmia and Mazury Oncology Centre, Olsztyn, Poland, phone: 511748938, e-mail: pstef1@o2.pl

\begin{abstract}
Large intestine polyps are commonly found during colonoscopies. Pedunculated colon polyps can be totally removed using an endoscopic invasive technique. A problem arises when the pendulated polyp contains cancerous infiltration. The aim of the article was a presentation of the clinical decision process concerned with the presence of cancer invasion tissue within colorectal polyps. Review of literature source and presentation of histological sample photography. A correct interpretation of the pathomorphological protocol is crucial for the therapeutic decision, which should be consistent with the actual recommendations of gastroenterological societies. Local treatment is considered as complete when the adenocarcinoma is well or moderately differentiated without any microinvasion of blood and lymphatic vessels and the resection margin is more than $1 \mathrm{~mm}$ from the cancer tissue infiltration. In the contemporary clinical practice patients with a colon polyp require rational clinical decisions, which are based on the actual recommendations.
\end{abstract}

\section{Introduction}

The current secondary prevention of colorectal cancer involves colonoscopy examinations. During this examination, the mucosa of large intestinal wall is controlled, and their condition is assessed, especially the potential presence of polypoid or neoplastic lesions. Endoscopic biopsy is performed when the mucosa is affected by inflammation, or when polypoid lesions, adenomas, or tumours are present. Pendulated polyps of the colon or rectum can be removed totally using an endoscopic invasive technique. Then, the histopathological examination evaluates potential dysplastic or neoplastic tissue presence in such endoscopically resected polyps. The infiltration of pathological tissue affects parts of the polyp's structure, and the clinician must correctly interpret the pathomorphology report to assess the stage of the tumour and prepare the final treatment decision. These decisions vary from referral patient observations by endoscopy monitoring to classifying the patient for a surgical procedure - segmental resection of the large intestines. This implies that the decision should be rational, consistent with the current treatment recommendations and the principles of evidence-based medicine.

\section{Discussion}

The normal epithelium of the large intestines is the simple columnar epithelium. It consists mainly of absorptive cells and Goblet cells. The columnar absorptive cells have distinct differentiation of the surface part. The apical surface of the cell is multiplied by the microvilli and adapted to absorb water and the other substances while the lateral surfaces ensure further transport of water and the other substances to the intercellular space; moreover, via the intercellular junctions, they form a dense and regular arrangement of the epithelial cells. The Goblet cells are unicellular glands that produce and secrete the mucus, which is a protective and lubricant layer covering the mucosal surface. 
The mucosa lining the internal lumen of the intestine is arranged in the intestinal crypts, which are deep indentations of the epithelium, forming simple tubular glands. The epithelium lines on the lamina propria which is composed of loose connective tissue with blood and lymphatic vessels and a thin layer of smooth muscles- the muscularis mucosae [1].

The structural distortion of the mucosa that is seen in an endoscopic examination has a tissue mass shape called a polyp. Depending on the shape and presence of the connecting pedicle, the polyp is called pedunculated, semi-pedunculated, sessile, or flat, respectively. Proliferations of the intestinal epithelium, in which produce cancer development, originate from adenomas or serrated lesions [2].

Initially, because of the adenomatous polyposis coli $(A P C)$ gene mutation and the occurrence of subsequent mutations (of the suppressor genes and protooncogenes), uncontrolled proliferation of epithelial cells takes place. Within the mucosa, proliferating cells form adenomatous lesions. A different degree of distortions of cellular morphology is found, including variations in the shape and size of the nuclei. The regular arrangement and normal structure of the glandular crypts are disturbed by lesions, and the sum of these morphological changes is called as dysplasia or intraepithelial hyperplasia. The severity of mucosal distortions is referred to as low-grade or high-grade dysplasia. Depending on the surface shape of the polypoid structures as development of the glandular tubules or visible villi, they are divided into 3 subtypes: tubular adenomas, villous adenomas, or tubulovillous adenomas, depending on the predominant component. These polypoid lesions have a potential for neoplastic transformation in the adenoma-cancer sequence [3].

The mutations in the mutator genes group, mainly $M S H 2$ and $M L H 1$, result in the development of serrated lesions. This name originates from a microscopic image - the epithelium has different heights of cells which form the glands, and these lumen resemble the teeth of a saw [3].

The probability of a malignant neoplasm significantly increases with larger polyps and the presence of a villous component. The presence of adenoma with the following criteria: size $\geq 1 \mathrm{~cm}$ and/or high-grade dysplasia and/or the villous formation $\geq 20 \%$, is considered as high risk of cancer development [4].

The polyps can be single, but in genetically determined alternations they can be multiple or even uncountable when the internal surface of the large intestine is entirely lined by them.

Today, colonoscopy is carried out as a diagnostic investigation in patients with specific symptoms: pain in the abdominal cavity, bleeding from the lower gastrointestinal tract or faecal occult blood, hypochromic anaemia, changes in the consistency of faeces, changes in the frequency of stools, and disturbances of the gastrointestinal transit time.

Furthermore, since 2000 in Poland, colonoscopy has been a part of colorectal cancer prevention to facilitate the early diagnosis of this neoplasm. This is carried out within the screening program, under the invitation (for people aged 55-64 years) and without invitation (upon patient's request) [5].

If any abnormalities in the large intestine mucosa (inflammation, polyp, and neoplasm) are detected, tissue samples are collected due to the histopathological evaluation. The polyp should be collected whole for a further histopathological verification if it is not too large for the endoscopic loop.

Colorectal polyps detected during colonoscopies performed under the screening programs are a common finding and the incidence is $19.4 \%$, including adenomas which were detected in $6.4 \%$ as well as colorectal cancers $-0.9 \%$. Cancers were diagnosed mostly in early-stage, $1^{\circ}-47.3 \%[6]$.

The incidence of colorectal polyps as well as the risk of cancer increase with the age of the persons recruited to the endoscopy screening [6]; therefore, the correct evaluation of a polyp and potential malignant colorectal polyp is very important. The rules of the protocol in the case of colon polyps were developed by the European Commission and published in a monography in 2020. They were later adopted as recommendations of the National Societies for Gastroenterology [4, 7].

Depending on the number of polyps, their size (less than $1 \mathrm{~cm}, 1-2 \mathrm{~cm}$, and bigger than $2 \mathrm{~cm}$ ), confirmation of adenoma and/or high-grade dysplasia and/or villous arrangement, the patient is qualified to the following groups: high, average, and low risk of neoplastic transformation and the potential development of colorectal cancer. The appropriate colonoscopy follow-up examinations are recommended, respectively, at 1-, 3-, and 10-year intervals. In the case of large polyps that can be resected in parts by using the "bite-by-bite" endoscopic polypectomy technique, the resection site should be tattooed, and the surgical scar should be examined after 2-3 months [7] (Table I).

In clinical practice, the problem with the decision occurs when the pendulated polyps has a cancerous infiltration. A proper interpretation of such a finding is critical for the course of the patient's case.

According to the pathological assessment, the stage of a neoplasm is evaluated using the $7^{\text {th }}$ edition of TNM AJCC/UICC. The infiltration limited to the mucosa (intraepithelial) is assigned as pTis stage, whereas the in- 
filtration of cancer into the lamina propria (including the muscularis mucosae) and deep penetration into the submucosa is considered as pT1, the first stage of invasive cancer. The head and stalk of the polyp are composed from the mucosa and the submucosa, and due to this the infiltration which is limited only to the polyp structure, without penetration into the wall of the large intestine, could be estimated as pTis or PT1 stage, respectively.

In pathomorphology analysis, the depth of cancerous infiltration within the pedunculated polyp is assessed using the Haggitt classification [8] (Figure 1). Haggitt level 4 is reserved for the infiltration of cancer below the polyp stalk, or it refers to squat polyps (Table II).

The submucosal infiltration of the intestinal wall is a starting point of the Kikuchi classification, which is used to assess squat, sessile, and semi-sessile polyps [9] (Table III).
After resection of the polyp, the local cancer treatment is considered as completed when all the following conditions are met: the presence of well or moderately differentiated tubular adenoma (malignancy stage G1 or G2), without vascular micro-invasion, and resection margin $>1 \mathrm{~mm}$ from the cancer infiltration. When the above-mentioned criteria are met, the patient should be examined after 3 and 6 months and then redirected for further colonoscopy monitoring at 1-year intervals [4, 7].

The resection site of a malignant polyp (scar) should be tattooed directly during colonoscopy or 7-14 days after the first resection date. A tattoo is extremely helpful in finding the site during a possible surgical procedure or further endoscopy follow-up [10].

The strongest parameters indicating that the neoplastic tissue has been left after polypectomy and subsequent risk of local recurrence is high, at $>20 \%$, (each of the points $1-3$ ) and $8-15 \%$ (point 4) are: 1 ) resection

Table I. Eligibility of the patients for the risk groups (points 1-3) and respective recommendations for the endoscopic follow-up, according to the recommendations of the Polish Society of Gastroenterology [7]

\begin{tabular}{|c|c|c|c|}
\hline Risk group & Number of polyps & Polyp size & Next colonoscopy \\
\hline 1. Low risk & $\begin{array}{c}\text { 1-2 tubular adenomas; low-grade } \\
\text { dysplasia }\end{array}$ & Smaller than $10 \mathrm{~mm}$ & $\begin{array}{l}\text { Without supervision, the next } \\
\text { prophylactic colonoscopy in } 10 \text { years }\end{array}$ \\
\hline \multirow[t]{3}{*}{ 2. Average risk } & 3-4 tubular adenomas & Smaller than $10 \mathrm{~mm}$ & \multirow[t]{3}{*}{ Examination in 3 years } \\
\hline & $\begin{array}{c}1 \text { adenoma or more with high-grade } \\
\text { dysplasia and/or with villous component }\end{array}$ & & \\
\hline & 1 adenoma or more & $10-20 \mathrm{~mm}$ & \\
\hline \multirow[t]{2}{*}{ 3. High risk } & 5 adenomas or more & Smaller than $10 \mathrm{~mm}$ & \multirow[t]{2}{*}{ After 1 year [7] } \\
\hline & 1 adenoma or more & Over $20 \mathrm{~mm}$ & \\
\hline \multicolumn{3}{|c|}{ "Bite-by-bite" polypectomy of sessile and flat polyps } & After 2-3 months \\
\hline \multicolumn{3}{|c|}{ Malignant colorectal polyp (when the criteria for oncological endoscopic resection are met) } & $\begin{array}{l}\text { First examination after } 3 \text { months, the } \\
\text { next after } 6 \text { months, and the following } \\
\text { examinations after } 12-24 \text { months [10] }\end{array}$ \\
\hline
\end{tabular}

Table II. The Haggitt classification for the assessment of cancerous infiltration within the pedunculated polyp [8]

\begin{tabular}{l}
$\begin{array}{c}\text { Carcinoma invading through the muscularis mucosae into the submucosa, but limited to the head of the polyp } \\
\text { (above the junction between the adenoma and its stalk) }\end{array}$ \\
\hline $\mathbf{3}$ Carcinoma invading to the level of the neck of the adenoma (junction between adenoma and its stalk) \\
\hline $4 \quad$ Carcinoma invading any part of the stalk \\
\hline
\end{tabular}

Table III. The modified Kikuchi classification, used for sessile polyps to stage cancer infiltration in the submucosa of the large intestine wall $[9,10]$

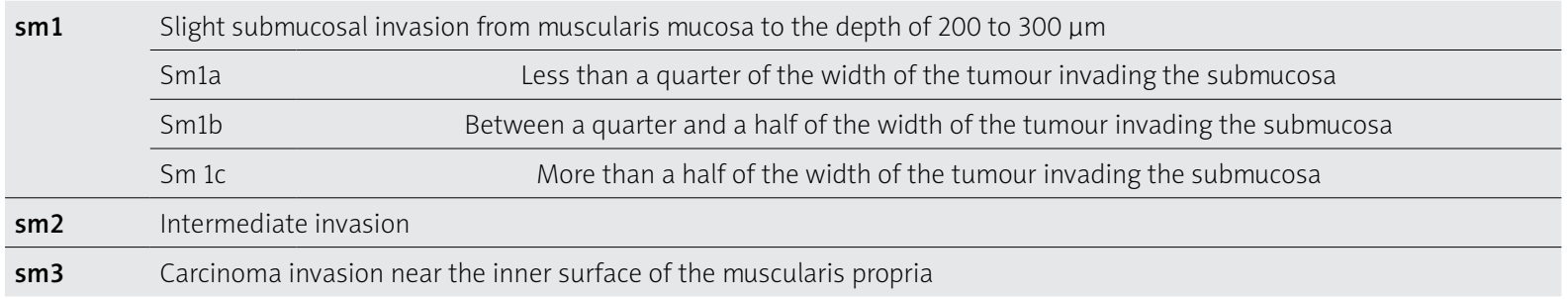



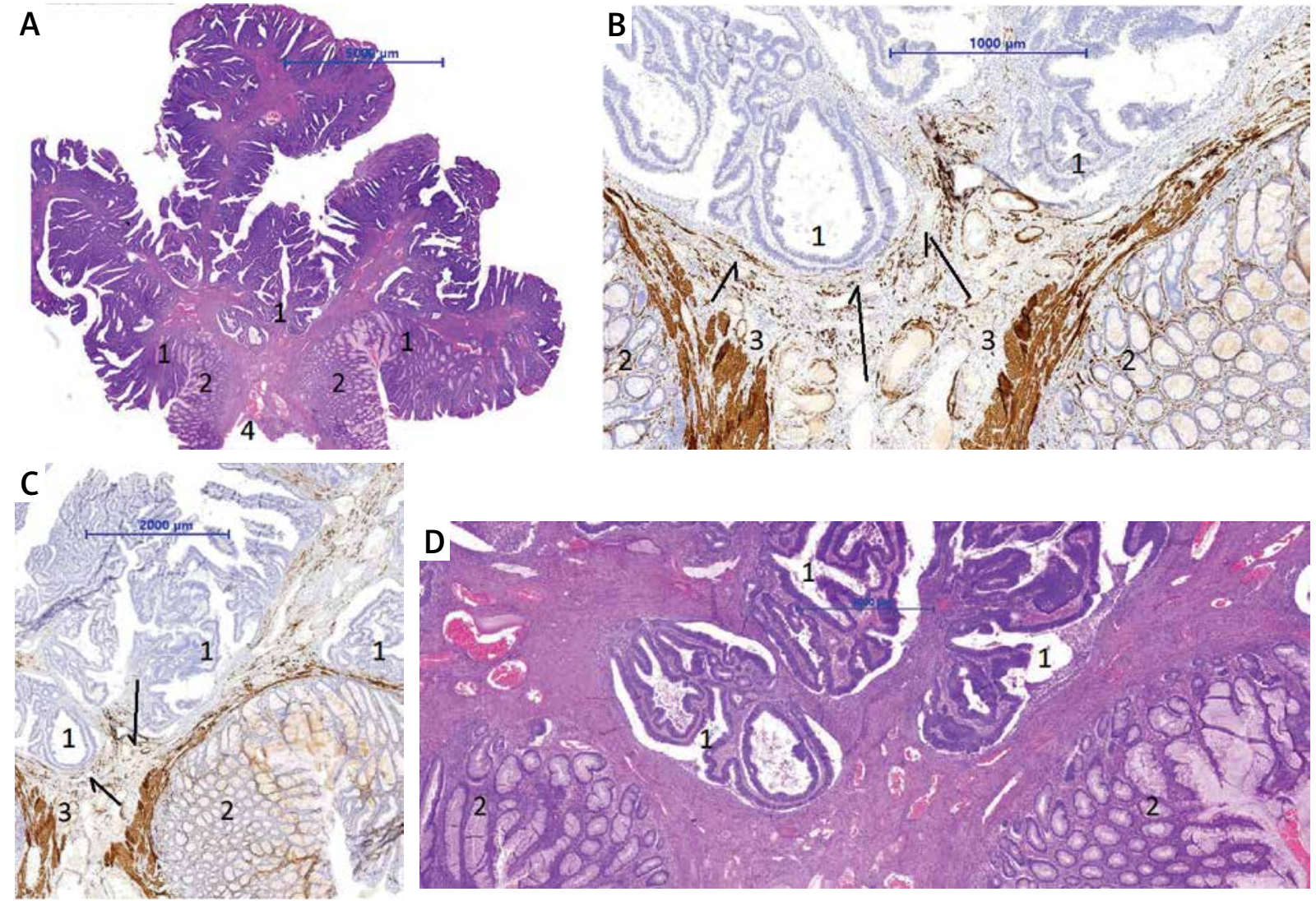

Figure 1. Pedunculated colon polyp, assessed with the Haggitt classification as level 3. A, D - H + E staining; the subsequent magnifications show infiltration of the polyp stalk by cancerous tissue (numbers 1); $A$, at the stalk level, there is regular intestinal epithelium (numbers 2), and the margin of the polyp resected with the endoscopic loop is tagged with the number 4. B, C - Immunohistochemical staining against desmin; to demonstrate smooth muscle tissue of the muscularis mucosae (numbers 3 ), the arrows indicate destruction of the muscularis mucosae from the cancer infiltration. The magnification bar: A - $5000 \mu \mathrm{m}, \mathrm{B}-1000 \mu \mathrm{m}$, C $-2000 \mu \mathrm{m}$, and D - $1000 \mu \mathrm{m}$ is labelled in each photo, respectively

margin < $1 \mathrm{~mm}, 2$ ) pedunculated polyp, Haggitt level 4, 3) sessile polyp, Kikuchi 3, 4) poor differentiation.

The above-mentioned factors imply that segmental large intestine resection should be performed if the general patient's condition allows for this procedure.

The other factors with lesser significance include the following: the sessile type of polyp - Kikuchi, sm2, lymphovascular invasion, mucinous tumour, and tumour budding [10].

Most patients with the diagnosis "cancer within colon polyp" are proceed using the special regulations of the "fast track for oncological diagnosis and treatment". Based on the performed examinations: computed tomography (CT) scan of the thorax, abdomen cavity, and pelvis plus carcinoembryonic antigen (CEA) level, which preclude or confirm cancer dissemination, the decision concerning further treatment is made. If the lesion is located at the rectum level, endorectal ultrasound (EUS) or magnetic resonance imaging (MRI) should be carried out as a part of the procedure. The decision is taken during the oncology consultation, in which the patient and oncological team (surgical oncologist, clinical oncologist, and radiotherapist) take part. In the "cancer within colon polyp" case, a correct interpretation of colonoscopy and histopathological reports is crucial, and the decisions should be consistent with the recommendations of the societies for gastroenterology as well as colorectal surgery. This decision also includes the risk analysis of the potential surgery and the perioperative complications with regard to the patient's age and general condition. At the same time, the factors indicating persistent cancer tissue in the margin of excision and/or a substantial risk for local cancer recurrence and, consequently, the strong need for surgical intervention with segmental intestinal resection and regional lymph draining cannot be ignored. The final decision about management is taken by a well-informed patient who has full knowledge of their clinical situation. 


\section{Conclusions}

In the contemporary clinical practice, the management of the patient with a colon polyp, both diagnosis and subsequent follow-ups, require cooperation between an endoscopist physician and a pathologist. The presence of cancerous tissue in the polyps warrants the participation of a radiologist and a surgical oncologist. This is an example of the multidisciplinary management that allows rational clinical decisions to be taken based on current recommendations.

\section{Acknowledgments}

The authors declare no conflict of interest.

\section{References}

1. Mescher A, Junqueira's Basic Histology Text \& Atlas. $14^{\text {th }}$ ed. McGraw-Hill Medical 2016; 318-24.

2. WHO Classification of Tumours Editorial Board, WHO Classification of tumours. Digestive System Tumours. Fifth Edition. IARC, Lyon 2019.

3. Mróz A. Diagnostyka różnicowa zmian przedrakowych: polipy i zespoły polipowatości jelita (zespoły polipów uwarunkowanych dziedzicznie). Pol J Pathol 2014; 65: 12-25.

4. Segnan N, Patnick J, von Karsa L. (eds.). European guidelines for quality assurance in colorectal cancer screening and diagnosis - first edition. European Commission, Publications Office of the European Union, Luxembourg 2010.

5. The Resolution of the Council of Ministers of 3 November 2015 on establishing the multiannual program for 2016-2024 under the name "National Program for Eradication of Neoplastic Diseases" (www.mz.gov.pl/wp-content/uploads/2015/12/ Uchwala-Nr-208-NPZCHN-2016-2024.pdf).

6. Pox PC, Altenhofen L, Brenner $\mathrm{H}$, et al. Efficacy of a nationwide screening colonoscopy program for colorectal cancer. Gastronterology 2012; 142: 1460-7.

7. Kamiński MF, Reguła J, Bartnik W, et al. Wytyczne Polskiego Towarzystwa Gastroenterologii dotyczące nadzoru kolonoskopowego po polipektomii - adaptacja wytycznych europejskich. Gastroenterol Klin 2011; 3: 55-62.

8. Haggitt RC, Glotzbach RE, Soffer EE, Wruble LD. Prognostic factors in colorectal carcinoma arising in adenomas: implication for lesion removed endoscopic polypectomy. Gastroenterology 1985; 89: 328-36.

9. Kikuchi R, Takano M, Takagi K, et al. Management of early invasive colorectal cancer, risk of recurrence and clinical guidelines. Dis Colon Rectum 1995; 38: 1286-95.

10. Williams JG, Pullan RD, Hill PG, et al. Management of the malignant colorectal polyp: ACPGBI position statement. Col Dis 2013; 15 (suppl. 2): 1-38.

Received: 27.01.2021

Accepted: 7.02 .2021 